\title{
Inflammatory milieu in contrast-induced nephropathy: a prospective single-center study
}

This article was published in the following Dove Press journal: International Journal of Nephrology and Renovascular Disease

\author{
Ashraf O Oweis' \\ Sameeha A Alshelleh² \\ Ammar K Daoud' \\ Mahmoud M Smadi ${ }^{3}$ \\ Karem H Alzoubi ${ }^{4}$ \\ 'Department of Internal Medicine, \\ Jordan University of Science and \\ Technology, Irbid, Jordan; ' 2Department \\ of Internal Medicine, the University of \\ Jordan, Amman, Jordan; ${ }^{3}$ Department \\ of Mathematics and Statistics, Jordan \\ University of Science and Technology, \\ Irbid, Jordan; ${ }^{4}$ Department of Clinical \\ Pharmacy, Jordan University of \\ Science and Technology, Irbid, Jordan
}

Correspondence: Ashraf $\mathrm{O}$ Oweis Department of Internal Medicine, Jordan University of Science and Technology, Irbid 221 10, Jordan

Tel +962 798737753

Fax +962 27095123

Email ashrafowais78@gmail.com
Background: Acute kidney injury (AKI) caused by contrast exposure is a common problem, which may cause a significant increase in patients in-hospital stay and therefore the cost of treatment. This study was conducted to evaluate the role of inflammation, inflammatory markers in predicting contrast induced nephropathy (CIN). This is a prospective study that was carried out in a major tertiary referral hospital in Jordan.

Methods: Clinical data, blood and urine samples were collected from all patients admitted to the cardiology unit. All patients who agreed to participate in the study had creatinine level analysis 48-72 hours after the procedure. The CIN was defined as an increase in serum creatinine by $25 \%$ or $44 \mu \mathrm{mol} / \mathrm{L}$ from the baseline within $48-72$ hours after the contrast administration. Patients with stage 4, 5 renal failure, patients on dialysis, and patients with recent intravenous contrast use, active infection or cancer were excluded from the study.

Results: Of the total 202 patients, 30 (14.8\%) developed CIN. The incidence rate was $21.1 \%$ among females and $12.4 \%$ among males. In the multivariate analysis, beside eGFR, diuretics, and alkaline phosphatase, IL-33 was significantly associated with CIN, while the other cytokines did not to show this an association.

Conclusion: Serum level of IL-33 was a significant predictor for development of CIN. Good clinical judgment and high serum levels of IL-33 may stratify patients into low and high risk for CIN.

Keywords: acute kidney injury, contrast, cytokines, cardiac catheterization

\section{Introduction}

Contrast-induced nephropathy (CIN) is one of the major causes of acute kidney injury (AKI) in hospitalized patients. The mechanism of this injury is multifactorial; ${ }^{1}$ osmolality or the type of contrast media used may play a role in developing CIN., ${ }^{2,3}$ Risk factors for CIN include abnormal kidney function at baseline ${ }^{4}$ and diabetes. In addition, the use of certain drugs such as angiotensin converting enzyme inhibitors or diuretics may increase the risk for CIN. ${ }^{5}$ A number of tests have been proposed to predict CIN, including hemoglobin, ${ }^{6}$ serum albumin, ${ }^{7}$ and alkaline phosphatase. ${ }^{8}$

Cytokines of innate immunity have been proposed to predict coronary artery disease (CAD) in patients with already established disease ${ }^{9}$ or in healthy subjects, ${ }^{10}$ as a marker of active inflammatory processes. Plasma neutrophil gelatinase-associated lipocalin (NGAL), which is a new biomarker used to identify patients at risk for AKI, was shown to be elevated in patients with CAD and heart failure. ${ }^{11}$ In patients with atherosclerosis, CAD manifested as elevated cytokine levels may predispose to worse renal outcome after cardiac catheterization. ${ }^{12}$ The aim of this study is to evaluate the possible role of inflammatory milieu, manifested by high C-reactive protein (CRP), 
multiple cytokines (interleukin [IL]-1 $\alpha$, IL-6, IL-19, IL-20, IL-21, IL-22, and IL-33), and NGAL levels, in increased risk for CIN.

\section{Patients and methods Study population}

An informed consent was obtained from all our participating patients. The study protocol was approved by the ethics committee and the Institutional Review Board at King Abdullah University Hospital, Jordan, and has been performed in accordance with the ethical standards of the 1964 Declaration of Helsinki and its later amendments. Using prospective observational design, between June 2015 and January 2016, we approached and evaluated 1,810 patients admitted to the cardiology ward in a tertiary referral hospital for cardiac catheterization (indications included acute coronary syndrome such as unstable angina, non-ST elevation myocardial infarction, STelevation myocardial infarction), who only used low-osmolality contrast media (CM) (Lopamidol, Bayer, Germany). Patients with stage 4, 5 renal failure, patients on dialysis, and patients with recent intravenous contrast use, active infection, or any type of cancers were excluded from the study. After applying the inclusion and exclusion criteria, 326 patients agreed and signed the consent to participate in the study.

\section{Study protocol and definitions}

All patients were assessed and evaluated at admission. Vital signs were recorded at admission and at the time of the procedure. Data regarding patients' demographics, comorbidities, and medication history were collected from the patients at the time of admission. Laboratory tests including complete blood count, kidney function, liver function, random blood sugar, HbA1c, uric acid, alkaline phosphatase, thyroid function, parathyroid hormone, 1,25 dihydroxyvitamin D3, and urine analysis were performed. Lipid profile was done at the time of admission if patients had been fasting for at least 12 hours; otherwise, it was done the next morning. Renal function was assessed using estimated glomerular filtration rate which was calculated using the Modification of Diet in Renal Disease equation. ${ }^{13,14}$ Echocardiography to measure left ventricular ejection fraction was done within 1 week of the procedure. The choice of renal protective measures was left to the treating cardiology team.

Patients had blood withdrawn 48 hours after the procedure for their creatinine level. CIN was defined as an increase in serum creatinine by $>25 \%$ or $44 \mu \mathrm{mol} / \mathrm{L}$ from the baseline level (48-72) hours after contrast administration, without any other obvious cause. ${ }^{15}$ Based on the lab cutoff, patients with vitamin D below $20 \mathrm{ng} / \mathrm{mL}$ were considered to be vitamin D deficient. Previous contrast use was defined as intravenous contrast administration within 1 week before the admission. Of the initial 326 patients included, 202 patients had their second sample taken and, thus, were eligible to continue in the study.

\section{Cytokine measurements}

At the time of procedure, serum was taken for CRP analysis using qualitative and semi-quantitative latex method (Linear, Montgat, Spain). The titer is expressed as the reciprocal of the highest dilution showing macroscopic agglutination, with the normal levels for adults being $<6 \mathrm{mg} / \mathrm{L}$. The procedure for CRP measurements was conducted in accordance with the manufacturer's datasheet.

Remaining serum was frozen in aliquots at $-80^{\circ} \mathrm{C}$ until further work was performed. The cytokine NGAL level was measured after dilution to 1:20, and other cytokines (IL-1 $\alpha$, IL-6, IL-19, IL-20, IL-21, IL-22, and IL-33) were measured directly without dilution of the sample according to the manufacturers' instructions. Cytokines' levels in serum were determined using enzyme-linked immunosorbent assay. Procedures of each cytokine immunoassay, including reagent and standard preparations, were conducted following instructions in the manufacturers' datasheets. OD of each sample was determined using enzyme-linked immunosorbent assay reader at $450 \mathrm{~nm}$ wavelength. The manufacturer information is as follows: IL-1 $\alpha$ (R\&D Systems, Inc., Minneapolis, MN, USA), IL-6 (R\&D Systems), IL-19 (R\&D Systems), IL-20 (R\&D Systems), IL-21 (eBiosience, San Diego, CA, USA), IL-22 (R\&D Systems), IL-33 (R\&D Systems), and NGAL (RayBio, Norcross, GA, USA).

\section{Statistical analysis}

All analyses were performed using SPSS (version 20; IBM Corporation, Armonk, NY, USA). Data were described using means and SD for continuous variables and percentages for categorical variables. For the purpose of the study, patients were divided into two groups: patients with CIN and patients without CIN. An independent-samples $t$-test was performed to compare the means of continuous variables in the two groups. A chi-squared test of independence was performed to examine the relation between the incidence rates of CIN (with and without $\mathrm{CIN}$ ) according to the demographic, clinical, and other relevant characteristics of the participants. Multivariate binary logistic regression was conducted to measure and determine the influence of factors associated with CIN. A $P$-value $<0.05$ was considered statistically significant. 


\section{Results}

\section{Patients' characteristics}

Patients ( $\mathrm{N}=202,28.2 \%$ females and $71.8 \%$ males) were enrolled in the study, and were examined at admission and after 48 hours of the procedure. Their age ranged between 29 and 87 years, with a mean \pm SD of $55.8 \pm 9.7$ years. The demographic and clinical characteristics of the participants are shown in Table 1. About two-thirds (68.8\%) of patients had hypertension and almost half of them (47.0\%) had CAD.

\section{Incidence of CIN}

Approximately $14.8 \%(n=30)$ of the patients developed CIN. The incidence rate was $21.1 \%$ among females and $12.4 \%$ among males. Table 2 shows the incidence rate of CIN according to demographic, clinical, and relevant characteristics of the participants. The incidence rate did not differ significantly according to the studied variables, except for use of diuretics. The incidence rate was significantly higher among patients who were on diuretics compared to those who were not on diuretics $(21.3 \%$ vs $11.0 \%, P=0.047)$. As per the cardiologist's decision, $10.9 \%$ of patients received hydration as a therapy for CIN.

\section{Factors associated with CIN}

We evaluated the role of inflammatory biomarkers (CRP, IL-1 $\alpha$, IL-6, IL-19, IL-20, IL-21, IL-22, IL-33, NGAL) and the incidence of CIN.

The levels of different biomarkers are shown in Table 3 . In univariate analysis, IL-33 and NGAL showed significant impact on CIN. Patients with CIN had a significantly lower mean creatinine level on admission $(73.3 \mu \mathrm{mol} / \mathrm{L}$ for $\mathrm{CIN}$ vs $87.6 \mu \mathrm{mol} / \mathrm{L}, P=0.01$ ), higher estimated glomerular filtration

Table I Demographic, clinical, and relevant characteristics of the participants

\begin{tabular}{lll}
\hline & $\mathbf{n}$ & $\%$ \\
\hline $\begin{array}{l}\text { Age, mean (SD) } \\
\text { Gender }\end{array} \quad$ Female & $57.8(9.7)$ & \\
$\quad$ Male & 145 & 28.2 \\
Smoking & & 71.8 \\
$\quad$ No & 92 & \\
$\quad$ Current & 79 & 45.8 \\
$\quad$ Past & 30 & 39.3 \\
Diabetes mellitus & 88 & 14.9 \\
Hypertension & 139 & 43.6 \\
Congestive heart failure & 54 & 68.8 \\
Cerebrovascular accident & 21 & 26.9 \\
Coronary artery disease & 95 & 10.4 \\
\hline
\end{tabular}

rate, and lower parathyroid hormone (PTH) level, compared to those who did not develop CIN. In multivariate analysis, IL-33 was a statistically significant predictor of $\mathrm{CIN}(P=0.001)$. For

Table 2 The incidence rate of contrast-induced nephropathy according to demographic, clinical, and relevant characteristics of the participants

\begin{tabular}{|c|c|c|c|c|c|}
\hline & \multicolumn{4}{|c|}{$\begin{array}{l}\text { Contrast-induced } \\
\text { nephropathy }\end{array}$} & \multirow[t]{3}{*}{$P$-value } \\
\hline & \multicolumn{2}{|l|}{ No } & \multicolumn{2}{|c|}{ Yes } & \\
\hline & $\mathbf{n}$ & $\%$ & $\mathbf{n}$ & $\%$ & \\
\hline Gender & & & & & 0.120 \\
\hline Female & 45 & 78.9 & 12 & 21.1 & \\
\hline Male & 127 & 87.6 & 18 & 12.4 & \\
\hline Smoking & & & & & 0.233 \\
\hline No & 74 & 80.4 & 18 & 19.6 & \\
\hline Current & 70 & 88.6 & 9 & 11.4 & \\
\hline Past & 27 & 90.0 & 3 & 10.0 & \\
\hline Diabetes mellitus & & & & & 0.978 \\
\hline No & 97 & 85.1 & 17 & 14.9 & \\
\hline Yes & 75 & 85.2 & 13 & 14.8 & \\
\hline Hypertension & & & & & 0.562 \\
\hline No & 55 & 87.3 & 8 & 12.7 & \\
\hline Yes & 117 & 84.2 & 22 & 15.8 & \\
\hline Congestive heart failure & & & & & 0.979 \\
\hline No & 125 & 85.0 & 22 & 15.0 & \\
\hline Yes & 46 & 85.2 & 8 & 14.8 & \\
\hline Cerebrovascular accident & & & & & 0.568 \\
\hline No & 155 & 85.6 & 26 & 14.4 & \\
\hline Yes & 17 & 81.0 & 4 & 19.0 & \\
\hline Coronary artery disease & & & & & 0.103 \\
\hline No & 87 & 81.3 & 20 & 18.7 & \\
\hline Yes & 85 & 89.5 & 10 & 10.5 & \\
\hline Angiotensin converting enzyme & & & & & 0.309 \\
\hline inhibitor & & & & & \\
\hline No & 114 & 87.0 & 17 & 13.0 & \\
\hline Yes & 58 & 81.7 & 13 & 18.3 & \\
\hline Angiotensin receptor blockers & & & & & 0.306 \\
\hline No & 135 & 86.5 & 21 & 13.5 & \\
\hline Yes & 37 & 80.4 & 9 & 19.6 & \\
\hline Diuretics & & & & & 0.047 \\
\hline No & 113 & 89.0 & 14 & 11.0 & \\
\hline Yes & 59 & 78.7 & 16 & 21.3 & \\
\hline $\begin{array}{l}\text { Nonsteroidal anti-inflammatory } \\
\text { drugs }\end{array}$ & & & & & 0.313 \\
\hline No & 157 & 84.4 & 29 & 15.6 & \\
\hline Yes & 15 & 93.8 & 1 & 6.3 & \\
\hline Statin & & & & & 0.980 \\
\hline No & 52 & 85.2 & 9 & 14.8 & \\
\hline Yes & 120 & 85.1 & 21 & 14.9 & \\
\hline Pre-procedure hydration & & & & & 0.568 \\
\hline No & 155 & 85.6 & 26 & 14.4 & \\
\hline Yes & 17 & 81.0 & 4 & 19.0 & \\
\hline eGFR, $\mathrm{mL} / \mathrm{min}$ & & & & & 0.863 \\
\hline$<60$ & 25 & 86.2 & 4 & 13.8 & \\
\hline$\geq+60$ & 147 & 85.0 & 26 & 15.0 & \\
\hline
\end{tabular}

Abbreviation: eGFR, estimated glomerular filtration rate. 
Table 3 CRP and interleukins based on CIN status

\begin{tabular}{|c|c|c|}
\hline Variable & CIN (+) & $\operatorname{CIN}(-)$ \\
\hline $\mathrm{CRP} \mathrm{mg} / \mathrm{L}$, mean $( \pm \mathrm{SD})$ & $8.3(12.9)$ & II.5 (37.9) \\
\hline $\mathrm{IL}-\mathrm{I} \alpha \mathrm{ng} / \mathrm{mL}$, mean $( \pm \mathrm{SD})$ & $2.1(2.7)$ & $2.4(3.2)$ \\
\hline IL-6 ng/mL, mean ( $\pm \mathrm{SD})$ & $2.7(2.4)$ & $3.1(2.8)$ \\
\hline IL-19 ng/mL, mean ( $(\mathrm{SD})$ & $5.8(8.2)$ & $9.5(11.3)$ \\
\hline $\mathrm{IL}-20 \mathrm{ng} / \mathrm{mL}$, mean $( \pm \mathrm{SD})$ & $2.9(4.0)$ & $2.1(3.3)$ \\
\hline $\mathrm{IL}-2 \mathrm{I} \mathrm{ng} / \mathrm{mL}$, mean $( \pm S D)$ & $29.7(20.0)$ & $40.2(36.6)$ \\
\hline $\mathrm{IL}-22 \mathrm{ng} / \mathrm{mL}$, mean $( \pm \mathrm{SD})$ & $4.7(5.9)$ & $5.9(8.6)$ \\
\hline $\mathrm{IL}-33 \mathrm{ng} / \mathrm{mL}$, mean $( \pm \mathrm{SD})$ & $2.2(2.2)$ & $1.0(1.5)$ \\
\hline $\mathrm{NGAL} \mathrm{ng} / \mathrm{mL}$, mean $( \pm \mathrm{SD})$ & $10.5(10.3)$ & $16.6(15.2)$ \\
\hline
\end{tabular}

Abbreviations: CIN, contrast-induced nephropathy; CRP, C-reactive protein; NGAL, neutrophil gelatinase-associated lipocalin.

each unit increase in IL-33, the odds of CIN increased by 1.4 times. On the other hand, CRP was not a statistically significant predictor of CIN. There was no significant difference between patients with CIN and those who did not develop CIN in terms of the contrast amount used $(99.8 \mathrm{~mL}$ for the CIN group vs $99.2 \mathrm{~mL}$ for the no CIN group, $P=0.95$ ).

\section{Discussion}

Serum creatinine is a poor marker for the evaluation and prediction of CIN as it takes time to increase and to be detected clinically. ${ }^{16}$ In the current study, IL-33 was identified as a possible predictive biomarker for increased risk of CIN.

Patients with cardiac disease usually have an inflammatory process, which can lead to atherosclerosis and CAD. ${ }^{17,18}$ A number of biomarkers have been proposed to evaluate inflammation, such as CRP. ${ }^{19}$ Though CRP was found to be an important marker for prognosis in cardiac disease, it was not a good predictor of CIN as indicated by current results.

Kidneys, in an inflammatory milieu, can be predisposed to more risk of injury, ${ }^{20}$ especially after CIN. ${ }^{12}$ In the current study, elevation of IL-33 was found to be associated with CIN. Other cytokines and inflammatory biomarkers including IL-1 $\alpha$, IL-6, IL-19, IL-20, IL-21, IL-22, IL-33, and NGAL were not found to predict CIN. Some of the former mentioned cytokines that were evaluated in cardiac diseases, including IL-1, IL-6, and IL-19-22, ${ }^{10,21-23}$ were found to have a potential role in predicting CIN..$^{21,24}$ However, as indicated by the current results, they are not good predictors for CIN.

IL-33 is a new IL-1 family member that was presented as an important molecule that invites the inflammatory cells to the kidney in cisplatin-induced nephropathy. ${ }^{25}$ It was found to be associated with the pathogenesis of various disorders, including autoimmune diseases, myocardial infarction, heart failure, and allergic pulmonary diseases. ${ }^{26} \mathrm{IL}-33$ is modulated by necrosis and apoptosis, which are the major features of CIN ${ }^{27}$ Current results suggest an important role for IL-33 in the course of CIN. Prevention of inflammation mediated by molecules such as IL-33 may represent the key target for preventing CIN.

The exact pathophysiologic mechanisms of CIN are not fully understood; however, inflammation, hypoxia, and oxidative stress constitute the main responsible pathways, especially in diabetic kidney disease (DKD). ${ }^{27}$ A previous study showed increased IL-33 levels in the kidney tissues and serum of diaetic rats with CIN. Thus, a role for IL-33 in the pathogenesis of CIN has been proposed. ${ }^{27} \mathrm{IL}-33$ is released from the necrotic cells, binds the interleukin 1 receptor on immune cells, and increases the secretion of cytokines, with resultant inflammation. ${ }^{28,29}$ Expression of IL-33 was typically located in the peritubular and intraglomerular capillaries of diabetic mice. The release of IL-33 from necrotic cells could induce autophagy, which can further balance the effects of increased apoptosis secondary to CIN in DKD. ${ }^{30,31}$

Conducting further analysis of IL-33 levels at time points earlier than 48 hours following CIN is suggested, which could spare the time to wait for serum creatinine to rise. Additionally, conducting a multicenter trial would be great to show replication of these observations.

\section{Conclusion}

Current results showed that serum level of IL-33 is a predictor for AKI after CIN. Thus, good clinical judgment and high serum level of IL-33 may be used to stratify patients into low and high risk for CIN.

\section{Acknowledgments}

This research was funded by Deanship of Research at Jordan University of Science and Technology (project number 539/2014). We would like to thank our cardiology colleagues, Dr Mohamad Jarrah and Dr Rashid Ibdah, for helping us in collecting blood samples during cardiac catheterization.

\section{Disclosure}

The authors report no conflicts of interest in this work.

\section{References}

1. Goldenberg I, Matetzky S. Nephropathy induced by contrast media: pathogenesis, risk factors and preventive strategies. CMAJ. 2005;172(11):1461-1471.

2. Bucher AM, de Cecco CN, Schoepf UJ, et al. Is contrast medium osmolality a causal factor for contrast-induced nephropathy? Biomed Res Int. 2014;2014:931413-8.

3. Aspelin P, Aubry P, Fransson SG, et al. Nephrotoxic effects in high-risk patients undergoing angiography. NEngl J Med. 2003;348(6):491-499.

4. Nakahashi H, Kosuge M, Sakamaki K, et al. Combined impact of chronic kidney disease and contrast-induced nephropathy on longterm outcomes in patients with ST-segment elevation acute myocardial infarction who undergo primary percutaneous coronary intervention. Heart Vessels. 2017;32(1):22-29. 
5. Kiski D, Stepper W, Brand E, Breithardt G, Reinecke H. Impact of reninangiotensin-aldosterone blockade by angiotensin-converting enzyme inhibitors or AT-1 blockers on frequency of contrast medium-induced nephropathy: a post-hoc analysis from the Dialysis-versus-Diuresis (DVD) trial. Nephrol Dial Transplant. 2010;25(3):759-764.

6. Ugur M, Uluganyan M, Ekmekci A, et al. Combination of hemoglobin and left ventricular ejection fraction as a new predictor of contrast induced nephropathy in patients with non-ST elevation myocardial infarction. Med Sci Monit. 2014;20:967-973.

7. Murat SN, Kurtul A, Yarlioglues M. Impact of serum albumin levels on contrast-induced acute kidney injury in patients with acute coronary syndromes treated with percutaneous coronary intervention. Angiology. 2015;66(8):732-7.

8. Schoppet M, Shanahan CM. Role for alkaline phosphatase as an inducer of vascular calcification in renal failure? Kidney Int. 2008;73(9):989-991.

9. Blankenberg S, Tiret L, Bickel C, et al. Interleukin-18 is a strong predictor of cardiovascular death in stable and unstable angina. Circulation. 2002;106(1):24-30.

10. Ridker PM, Rifai N, Stampfer MJ, Hennekens CH. Plasma concentration of interleukin- 6 and the risk of future myocardial infarction among apparently healthy men. Circulation. 2000;101(15):1767-1772.

11. Daniels LB, Barrett-Connor E, Clopton P, Laughlin GA, Ix JH, Maisel AS. Plasma neutrophil gelatinase-associated lipocalin is independently associated with cardiovascular disease and mortality in communitydwelling older adults: The Rancho Bernardo Study. J Am Coll Cardiol. 2012;59(12):1101-1109.

12. Kwasa EA, Vinayak S, Armstrong R. The role of inflammation in contrast-induced nephropathy. Br J Radiol. 2014;87(1041):20130738.

13. Levey AS, Bosch JP, Lewis JB, et al. A more accurate method to estimate glomerular filtration rate from serum creatinine: a new prediction equation. Modification of Diet in Renal Disease Study Group. Ann Intern Med. 1999;130(6):461-470.

14. Michels WM, Grootendorst DC, Verduijn M, Elliott EG, Dekker FW, Krediet RT. Performance of the Cockcroft-Gault, MDRD, and new CKD-EPI formulas in relation to GFR, age, and body size. Clin J Am Soc Nephrol. 2010;5(6):1003-1009.

15. Harjai KJ, Raizada A, Shenoy C, et al. A comparison of contemporary definitions of contrast nephropathy in patients undergoing percutaneous coronary intervention and a proposal for a novel nephropathy grading system. Am J Cardiol. 2008;101(6):812-819.

16. Parikh CR, Abraham E, Ancukiewicz M, Edelstein CL. Urine IL-18 is an early diagnostic marker for acute kidney injury and predicts mortality in the intensive care unit. J Am Soc Nephrol. 2005;16(10):3046-3052.
17. Danesh J, Whincup P, Walker M, et al. Low grade inflammation and coronary heart disease: prospective study and updated meta-analyses. BMJ. 2000;321(7255):199-204.

18. Ross R. Atherosclerosis--an inflammatory disease. $N$ Engl J Med. 1999;340(2):115-126.

19. Biasucci LM, CDC, AHA. CDC/AHA workshop on markers of inflammation and cardiovascular disease: application to clinical and public health practice: clinical use of inflammatory markers in patients with cardiovascular diseases: a background paper. Circulation . 2004;110(25):e560-e567.

20. Simmons EM, Himmelfarb J, Sezer MT, et al. Plasma cytokine levels predict mortality in patients with acute renal failure. Kidney Int. 2004;65(4):1357-1365.

21. Hsing CH, Hsieh MY, Chen WY, Cheung So E, Cheng BC, Chang MS. Induction of interleukin-19 and interleukin-22 after cardiac surgery with cardiopulmonary bypass. Ann Thorac Surg. 2006;81(6):2196-2201.

22. Luc G, Bard JM, Juhan-Vague I, et al. C-reactive protein, interleukin-6, and fibrinogen as predictors of coronary heart disease: the PRIME Study. Arterioscler Thromb Vasc Biol. 2003;23(7):1255-1261.

23. Bujak M, Frangogiannis NG. The role of IL-1 in the pathogenesis of heart disease. Arch Immunol Ther Exp. 2009;57(3):165-176.

24. Hudzik B, Szkodzinski J, Danikiewicz A, et al. Serum interleukin-6 concentration predicts contrast-induced nephropathy in patients undergoing percutaneous coronary intervention. Eur Cytokine Netw. 2010;21(2):129-135.

25. Akcay A, Nguyen Q, He Z, et al. IL-33 exacerbates acute kidney injury. J Am Soc Nephrol. 2011;22(11):2057-2067.

26. Lu J, Kang J, Zhang C, Zhang X. The role of IL-33/ST2L signals in the immune cells. Immunol Lett. 2015;164(1):11-17.

27. Demirtas L, Turkmen K, Kandemir FM, et al. The possible role of interleukin-33 as a new player in the pathogenesis of contrast-induced nephropathy in diabetic rats. Ren Fail. 2016;38(6):952-960.

28. Lamkanfi M, Dixit VM. IL-33 raises alarm. Immunity. 2009;31(1):5-7.

29. Moussion C, Ortega N, Girard JP. The IL-1-like cytokine IL-33 is constitutively expressed in the nucleus of endothelial cells and epithelial cells in vivo: a novel 'alarmin'? PLoS One. 2008;3(10):e3331.

30. Ali S, Nguyen DQ, Falk W, Martin MU. Caspase 3 inactivates biologically active full length interleukin-33 as a classical cytokine but does not prohibit nuclear translocation. Biochem Biophys Res Commun. 2010;391(3):1512-1516.

31. Lüthi AU, Cullen SP, Mcneela EA, et al. Suppression of interleukin-33 bioactivity through proteolysis by apoptotic caspases. Immunity. 2009;31(1):84-98.
The International Journal of Nephrology and Renovascular Disease is an international, peer-reviewed open access journal focusing on the pathophysiology of the kidney and vascular supply. Epidemiology, screening, diagnosis, and treatment interventions are covered as well as basic science, biochemical and immunological studies. The manuscript management system is completely online and includes a very quick and fair peer-review system, which is all easy to use. Visit http://www. dovepress.com/testimonials.php to read real quotes from published authors. 